\title{
Comparing the Effectiveness of Therapies in People With Secondary Progressive Multiple Sclerosis
}

Jessica Rice, MD, and Xinran Maria Xiang, MD

Neurology ${ }^{\circledR}$ 2021;97:e972-e974. doi:10.1212/WNL.0000000000012510

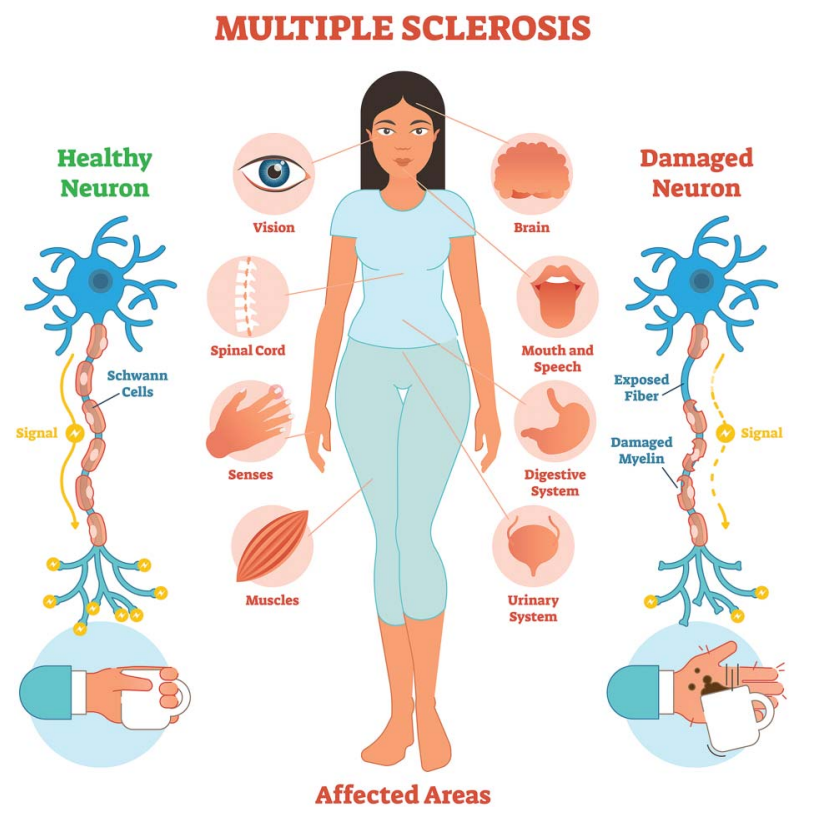

Secondary progressive multiple sclerosis (SPMS) is a phase of multiple sclerosis (MS) that may come after the relapsing-remitting phase. People in the relapsing-remitting phase of MS have recurring episodes (called relapses) of new or worsening neurologic symptoms. People who have SPMS tend to have fewer relapses, but their symptoms and disabilities slowly get worse over time. The shift between these 2 phases can be gradual and may even overlap. Because of this, some people have "active" SPMS, meaning they still have relapses in addition to slowly worsening disability. Current MS medicines, known as disease-modifying therapies (DMTs), are known to reduce the risk of relapses in people with relapsing-remitting MS, but the benefit of this treatment for people with SPMS is less clear. Recent studies have shown that some DMTs may help people with active SPMS. However, there have not been any previous studies comparing how effective different types of DMTs are for people with SPMS.

\section{What Did the Authors Study?}

The authors studied how effective several different MS treatments were at decreasing MS relapses. They also studied whether these treatments could reduce disability in people with either active or inactive SPMS. ${ }^{1}$

\section{How Was the Study Done?}

The authors used information from 2 large international databases to find a group of 1,000 people with active or inactive SPMS. They studied people who were treated with highly effective MS medicines (such as natalizumab, alemtuzumab, mitoxantrone, ocrelizumab, rituximab, cladribine, or fingolimod) or with less effective MS medicines (such as interferon $\beta 1 a$, interferon $\beta 1 b$, glatiramer acetate, or teriflunomide). They did
Related Article

Effects of High- and Low-Efficacy Therapy in

Secondary Progressive Multiple Sclerosis

http://dx.doi.org/10.1212/ WNL.0000000000012354 
not study people taking dimethyl fumarate. In this study, people were considered to have active SPMS if they had a relapse or a new MRI lesion in the 2 years before starting treatment. Then, the authors evaluated the number of MS relapses. They looked at how much disability worsened in each group over time to see if there was a difference. They also accounted for therapeutic lag. This is the length of time it takes MS medicines to become effective after a person with MS begins taking them. They did this so if any of the people they were studying had a relapse before the medication was working, it would not affect the results.

\section{What Did the Study Show?}

The researchers found that people with active SPMS taking highly effective medicines had fewer relapses than those taking the less effective medicines. However, people with inactive SPMS had no difference in the number of relapses. This was the case regardless of whether they took highly effective or less effective medicines for MS. Finally, people with active and inactive SPMS taking either type of MS medicine all had similar worsening of disability over the study period. In other words, taking a highly effective medicine helped reduce relapses in people with active (but not inactive) SPMS, but did not reduce disability in either group.

\section{Why Do These Findings Matter?}

The experience of living with MS can be different for everyone, and a person's needs may change over time. The findings of this study can help guide neurologists and people living with MS when choosing the right medication for them. Each medication has its own unique balance of benefits, risks, and side effects. In people with SPMS who are also having relapses, these results might help the individual feel more confident in choosing one of the highly effective medications. However, if a person is not having relapses, or the main goal of that patient's treatment is to slow worsening of disability over time, this study did not show that one group of medicines is better than another. Because of this, a wider range of treatment options can be considered for those patients. 


\section{About Multiple Sclerosis}

\section{What Is Multiple Sclerosis?}

Multiple sclerosis (MS) is a disorder in which the body's immune system produces inflammation that damages the brain, spinal cord, and optic nerves. The damage affects both the nerves and the myelin, which is a fatty substance that surrounds the nerves. This damage may result in a variety of neurologic symptoms. These symptoms can include weakness, numbness, difficulties with balance and walking, vision loss, and difficulties with bowel and bladder function.

Most people with MS are diagnosed between the ages of 20 and 50, and MS is more common in women than in men. It remains unclear what causes MS. MS is not a contagious or inherited disease. It appears that a combination of genetic and environmental factors such as smoking, obesity, and vitamin $D$ levels in childhood and early adulthood may play important roles in triggering MS.

\section{What Is Secondary Progressive MS?}

Most people with MS have relapsing MS. This means they have recurring episodes (called relapses) of new or worsening neurologic symptoms. The symptoms can last from days to weeks. They are followed by periods in between episodes when symptoms are stable or improving. Secondary progressive MS (SPMS) is a phase of MS that can come after the relapsing phase. In this phase, a person with MS has gradually increasing levels of disability, even when the person does not have a relapse, although someone in this stage may still have relapses as well. Among people with SPMS, those who still have relapses or new lesions (or abnormal spots) that develop in their brain or spinal cord as seen on MRI are considered to have active SPMS, whereas people with inactive SPMS do not have either relapses or new MRI activity.

Not everyone with relapsing MS will transition into SPMS. A number of factors may affect whether or when someone will make this transition. These risk factors include older age, longer disease duration, higher scores on tests that measure disability levels, and a faster rate of disability increase. ${ }^{2}$ There are no blood tests or imaging tests that can predict the disease course of someone who has MS. Sometimes it may be difficult to tell if someone is transitioning from relapsing MS to SPMS, and physicians often need to follow someone for years to be able to reach a definitive diagnosis of SPMS.

\section{What Are the Treatments for Multiple Sclerosis?}

Disease-modifying therapies (DMTs) used in the treatment of MS have been shown to decrease both the rate of new MS relapses and new areas of inflammation in the brain and spinal cord. So far, there are no therapies that can repair the damage from old relapses. There are now over 20 DMTs that are Food and Drug Administration-approved for relapsing forms of MS as well as active secondary progressive MS. One DMT, ocrelizumab, has been approved to treat primary progressive MS, and has shown modest benefit when it comes to decreasing disability progression in those with primary progressive MS. ${ }^{3}$ There are no DMTs that have shown a clear benefit for decreasing how fast someone's disability worsens for people with SPMS, as was seen in this study. Some DMTs are considered to be highly effective at reducing the risk for new relapses and include medicines such as natalizumab, alemtuzumab, ocrelizumab, rituximab, cladribine, and fingolimod. When compared to these highly effective therapies, some DMTs are considered to be less effective (such as interferon $\beta 1 \mathrm{a}$, interferon $\beta 1 \mathrm{~b}$, glatiramer acetate, and teriflunomide). Dimethyl fumarate is a DMT that is usually considered intermediate between these 2 groups. However, each of these DMTs comes with its own risks and side effects that should be taken into account when making the decision to start one of these DMTs. It is important for people living with MS to work closely with their neurologist to find the best medicine for them.

\section{For More Information}

Brain \& Life

brainandlife.org

Multiple Sclerosis Association of America mymsaa.org

National Multiple Sclerosis Society nationalmssociety.org

Multiple Sclerosis Foundation

msfocus.org

\section{References}

1. Roos I, Leray E, Casey R, et al. Effects of high- and low-efficacy therapy in secondary progressive multiple sclerosis. Neurology. 2021;97(9):e869-e880.

2. Fambiatos $A$, Jokubaitis $V$, Horakova $D$, et al. Risk of secondary progressive multiple sclerosis: a longitudinal study. Mult Scler J. 2020;26(1):79-90.

3. Montalban X, Hauser SL, Kappos L, et al; ORATORIO Clinical Investigators. Ocrelizumab versus placebo in primary progressive multiple sclerosis. N Eng/ J Med. 2017;376(3): 209-220. 


\section{Neurology}

\section{Comparing the Effectiveness of Therapies in People With Secondary Progressive Multiple Sclerosis \\ Jessica Rice and Xinran Maria Xiang \\ Neurology 2021;97;e972-e974 \\ DOI 10.1212/WNL.0000000000012510}

This information is current as of August 30, 2021

\section{Updated Information \& Services}

References

Subspecialty Collections

Permissions \& Licensing

Reprints including high resolution figures, can be found at: http://n.neurology.org/content/97/9/e972.full

This article cites 3 articles, 1 of which you can access for free at: http://n.neurology.org/content/97/9/e972.full\#ref-list-1

This article, along with others on similar topics, appears in the following collection(s):

Autonomic diseases

http://n.neurology.org/cgi/collection/autonomic_diseases

Information about reproducing this article in parts (figures,tables) or in its entirety can be found online at:

http://www.neurology.org/about/about_the_journal\#permissions

Information about ordering reprints can be found online:

http://n.neurology.org/subscribers/advertise

Neurology ${ }^{\circledR}$ is the official journal of the American Academy of Neurology. Published continuously since 1951 , it is now a weekly with 48 issues per year. Copyright @ 2021 American Academy of Neurology. All rights reserved. Print ISSN: 0028-3878. Online ISSN: 1526-632X.

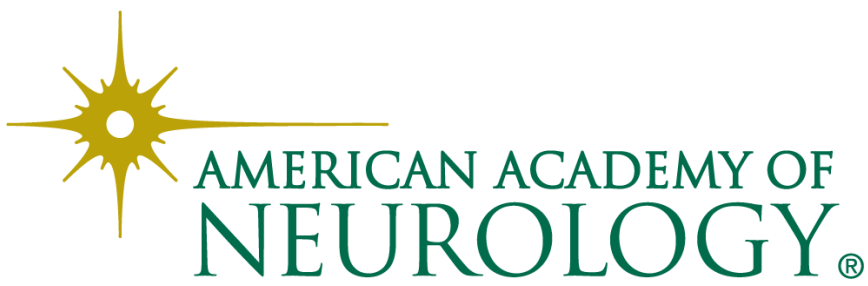

